\title{
Hemodiyaliz ve Periton Diyalizi Yapan Hastalarda Osteoporoz Sıklığı ve Osteoporoz Gelişmesini Etkileyen Faktörler
}

\author{
The Frequency of Osteoporosis in Hemodialysis and Peritoneal \\ Dialysis and Factors in Development of Osteoporosis
}

\author{
Bengisu ASLAN ${ }^{1}$, Funda SARI ${ }^{2}$
}

${ }^{1}$ Akdeniz üniversitesi Tıp Fakültesi İç Hastalıkları Anabilim Dalı, Romatoloji Bilim Dalı, Antalya

${ }^{2}$ Akdeniz üniversitesi Tıp Fakültesi İç Hastalıkları Anabilim Dalı, Nefroloji Bilim Dalı, Antalya

Yazışma Adresi

Correspondence Address

\section{Bengisu ASLAN}

Akdeniz Üniversitesi Tıp Fakültesi

İç Hastalıkları Anabilim Dalı,

Romatoloji Bilim Dalı, Antalya,

Türkiye

E-posta:

drbengisuunlu@gmail.com

Geliş tarihi \Received : 03.06 .2020 Kabul tarihi \ Accepted : 15.07.2020 Elektronik yayın tarihi $\quad: 12.07 .2021$ Online published

Bu makaleye yapılacak atıf: Cite this article as:

Aslan B, Sarı F. Hemodiyaliz ve periton diyalizi yapan hastalarda osteoporoz skklı̆̆ ve osteoporoz gelişmesini etkileyen faktörler. Akd Tip D 2021; $7(2): 277-282$

Bengisu ASLAN

ORCID ID: 0000-0001-6892-1090

Funda SARI

ORCID ID: 0000-0003-0128-3244

16-20 Ekim 2019 tarihleri arasinda Antalya da yapilan 36. Ulusal Nefroloji Kongresinde poster olarak kabul edilmiştir.

Bu çalışma, danışmanlığını Akdeniz Üniversitesi Tip Fakültesi, İç hastalıkları Anabilim Dalı Ögretim Üyesi Prof. Dr. Funda SARI nın yaptığ Dr Bengisu ASLAN a ait tipta uzmanlık tezinden üretilmiştir.
ÖZ

Amaç: Kronik böbrek hastalığı $(\mathrm{KBH})$ gittikçe prevalansı artan ve birçok sistemi etkileyen önemli bir sağlık sorunudur. KBH'nın neden olduğu sorunlardan biri de kemik mineral hastalıklarıdır. Birçok nedenden dolayı bu hastalarda osteoporoz sıklığı artmaktadır. Bu çalışmanın amacı hemodiyaliz uygulayan ve periton diyalizi uygulayan hastalarda osteoporoz sıklığını ve onu etkileyen risk faktörlerini değerlendirmektir.

Gereç ve Yöntemler: Akdeniz Üniversitesi Tıp Fakültesi Periton Diyalizi Polikliniği ve Hemodiyaliz Kliniğinde takip edilen kemik mineral hastalığı açısından riskli görülen Dual Enerji XRay Absorbsiyometri (DEXA)'si çekilen 18 yaşından büyük hastalar alınmıştır. Araştırmaya alınan toplam hasta sayısı 74'tür. 37 hasta periton diyalizi polikliniğinden, 37 hasta hemodiyaliz kliniğinden alınmıştır. Çalışmadan çıkarılma kriteri olarak KBH dışında herhangi bir nedene bağlı kemik mineral hastalığının olmasıdır. Bu hastalarda osteoporoz gelişmesini etkileyeceğini düşündüğümüz şu parametreler incelenmiştir: Yaş, menopoz yaşı, diyaliz süresi, sigara tüketimi, kalsiyum içeren veya içermeyen fosfat bağlayıcı kullanımı, kırık öyküsü, hemodiyaliz etkinliğini gösteren kt/v oranı, bikarbonat, hemoglobin, kreatinin, kalsiyum, fosfor, parathormon (PTH), trigliserid, düşük dansiteli lipoprotein (LDL) kolesterol, yüksek dansiteli protein (HDL) kolesterol, albümin, $25 \mathrm{OH}$ vitamin D düzeyleri ve DEXA'larındaki femur boynu vertebra L1-L4 T skor verileri SPSS23 programına yüklenmiştir. Bu verilerle uygun istatistiksel analizler yapılmıştır.

Bulgular: Çalışmamızda yer alan 74 hastanın 32'sinde (\%43) osteoporoz saptanmıștır. 32 osteoporozu olan hastanın 17'si kadın, 15’i erkektir. Osteoporozu olan hastalarda vücut ağırlığı (p:0,001), kalsiyum düzeyi (p:0,01), $25 \mathrm{OH}$ vitamin D seviyesi (p:0,039), kalsiyum içermeyen fosfat bağlayıcı kullanımı (p:0,042) osteoporoz ile ilişki olarak saptanmıştır. Diyaliz tipinin de katıldığı bu faktörlerle yapılan regresyon analizlerinde en önemli faktörün vücut ağırlı̆̆ı olduğu saptanmıştır. Vücut ağırlığı ne kadar azsa osteoporoz riski o kadar fazla tespit edilmiştir. Yaptığımız çalışmada periton diyalizi uygulayan hastalarda \%35 oranında daha az osteoporoz saptanmıştır (p: 0,159).

Sonuç: Son dönem böbrek hastalığı (SDBH) olanlarda osteoporoz önemli bir mortalite ve morbidite nedenidir. Bir çok nedenden dolayı bu hastalarda osteoporoz için uygun tedavi verilememekte ve osteoporoz gelişimi engellenememektedir. $\mathrm{O}$ yüzden; bu açıdan riskli olan hastalarda uygun renal replasman tedavi yöntemini belirlemek için yeni çalışmaların yapılması gerekmektedir.

Anahtar Sözcükler: Osteoporoz, Periton diyaliz, Hemodiyaliz

\begin{abstract}
Objective: Chronic kidney disease (CKD) is an important health problem with an increasing prevalence and affecting many systems. One of the problems caused by CKD is bone mineral diseases. For many reasons, the frequency of osteoporosis in these patients increases. The aim of this study is to evaluate the frequency of osteoporosis and the factors associated osteoporosis in hemodialysis and peritoneal dialysis.

Material and Methods: Patients older than 18 years old were taken, who were deemed risky in terms of bone mineral disease followed up at Akdeniz University Medical Faculty Peritoneal Dialysis Policlinic and Hemodialysis Clinic. The total number of patients enrolled in the study is 74.37 patients
\end{abstract}


were taken from the peritoneal dialysis outpatient clinic and 37 patients from the hemodialysis clinic. Exclusion criteria is bone mineral disease due to any cause other than CKD. The following parameters, which we think will affect the development of osteoporosis in these patients, have been studied: age, menopause age, dialysis duration, cigarette consumption, use of phosphate binders with or without calcium, history of fracture, bicarbonate, hemoglobin, creatinine, kt/v, calcium, phosphorus, parathormone (PTH), triglyceride, LDL cholesterol, HDL cholesterol, albumin, $25 \mathrm{OH}$ vitamin D levels and femoral neck vertebra L1-L4 T score data in DEXAs were loaded into the SPSS23 program. Appropriate statistical analyzes were made with these data.

Results: Osteoporosis was detected in $32(43 \%)$ of 74 patients in our study. Of the 32 patients with osteoporosis, 17 were female and 15 were male. In patients with osteoporosis, body weight (p: 0.001), calcium level (p: 0.01), 25 OH vitamin D level (p: 0.039), calciumfree phosphate binder use (p: 0.042) were found to be associated with osteoporosis. In regression analysis with these factors, in which dialysis type was also included, the most important factor was found to be body weight. The lower the body weight, the greater the risk of osteoporosis. In our study, 35\% less osteoporosis was detected in patients performing peritoneal dialysis (p: 0.159 ).

Conclusion: Osteoporosis is an important cause of mortality and morbidity in patients with end-stage kidney disease (SDBH). For many reasons, proper treatment for osteoporosis cannot be given in these patients and the development of osteoporosis cannot be prevented. That's why; New studies are needed to determine the appropriate renal replacement therapy in patients at risk in this regard.

Keywords: Osteoporosis, Peritoneal dialysis, Hemodialysis

\section{GIRIŞ}

Kronik böbrek hastalığı $(\mathrm{KBH})$ nedenine bağlı olmaksızın 3 ay veya daha fazla süren böbrek hasarının varlığı veya tahmini glomerüler filtrasyon hızının (eGFH) $60 \mathrm{ml} /$ $\mathrm{dk} / 1.73 \mathrm{~m}^{2}$ 'den düşük olması olarak tanımlanır. Kidney Disease Outcomes Quality Initiative (K/DOQI) kllavuzu ile KBH tahmini glomerüler filtrasyon hızı (eGFH) düzeyine göre beş evrede sinıflandırılmıştır. KBH Evre 5 eGFH'ın $15 \mathrm{ml} / \mathrm{dk} / 1,73 \mathrm{~m}^{2}$ 'nin altında olduğu son dönem böbrek yetmezliği aşamasıdır $(1,2)$. Son dönem böbrek yetmezliği gelişen hastalarda medikal tedavi yanında renal replasman tedavileri de uygulanmaktadır. Renal replasman tedavileri periton diyalizi, hemodiyaliz ve renal transplantasyondur.

$\mathrm{KBH}$ sistemik bir hastalık olup, klinik seyri boyunca birçok sistemi etkilemektedir. Bunlar; kardiyovasküler sistem, santral sinir sistemi, hematolojik sistem, gastrointestinal sistem, endokrin sistem, immun sistem ve kas-iskelet sistemi olarak sayllabilmektedir.

KBH'nda mortalite ve morbiditenin en önemli sebebi kardiyovasküler hastalıklar olup, kemik mineral bozuklukları da artmış mortaliteye katkı sağlamaktadır. Bu katkıyı hem kemik fraktür riskini arttırarak hem de kardiyovasküler hastalık risk artışına yol açarak sağlamaktadır. Bu bozukluk $\mathrm{KBH}$ mineral ve kemik bozuklukları (KBH-MBD) olarak tanımlanmaktadır (3).

KBH'na bağlı kemik mineral hastalıkları dört başlık altında toplanabilmektedir. Bunlar; yüksek döngülü kemik hastalı$\breve{g}$ 1, adinamik kemik hastalığı, osteomalazi ve miks üremik distrofidir. Kronik böbrek hastalarındaki mineral kemik bozukluklarından bir diğeri ise osteoporozdur. Osteoporoz düşük kemik kütlesi ve kemik dokusunun mikro mimari yapısının bozulması ile karakterize kemiğin yapısal yetmezliğidir. Kemik yapısının bozulmasına bağlı kemik frajil hale gelip kırılması kolaylaşmaktadır. Osteoporoz yaşlı hastalarda önemli bir sağlık sorunudur. Ciddi kas-iskelet ağrıları, fiziksel kapasitede de sınırlanma, artmış kırık riski nedeniyle hastaların hayat kalitesini negatif yönde etkilemektedir. Beyaz ırk, kadın cinsiyet, düşük vücut kitle indeksi (VKİ), meslek, sosyoekonomik durum, kişide ve annede geçirilmiş frajilite kırı̆̆ı öyküsü, beslenme tarzı, çay, kahve, sigara gibi alıskanlıklar, sedanter yaşam, kronik hastalıklar, aterosklerozis, steroid kullanımı gibi ek medikasyonlar osteoporoz için risk oluşturmaktadır. Evre 3-5 KBH'lı 70 yaş üzeri hastalarda da osteoporozun sıklığı $\% 53$ olarak tespit edilmiştir ve sıklığı gittikçe artmaktadır (4).

Osteoporoz için tanısal testler olarak DEXA, kantitatif bilgisayarlı tomografi, heel ultrasonografi, kemik biyopsisi kullanılabilir. Kemik biyopsisi altın standart olmasına rağmen, düşük maliyet, kesin tanı, kısa görüntü zamanı, düşük radyasyon dozu kullanımı gibi avantajları nedeni ile DEXA tanısal testler içinde en yaygın kullanılanıdır.

Son yıllarda yapılan çalışmalarda osteoporozun önemli bir morbidite nedeni olması ve yeni tedavi seçeneklerinin ortaya çıkması nedeni ile tanısal yaklaşım değişmiştir (5). 2017 KDIGO'da KBH'na sahip kişilerde osteoporoz için risk faktörleri varsa kemik mineral dansite ölçümü yapılması önerilmektedir (6). Böylece bu hastalarda kırık riski öngörülebilmektedir.

Bizim bu çalışma ile amacımız periton diyalizi veya hemodiyaliz yapan hasta grubunda osteoporoz sıklığını belirlemek ve bu hastalarda hangi faktörlerin osteoporozu arttırdığını tespit etmektir.

\section{YÖNTEM}

Bu çalışma için Akdeniz Üniversitesi Tip Fakültesi Klinik Araştırmalar Etik Kurulu Başkanlığı tarafindan değerlendirmeye alınarak yazılı olarak onaylanmıştır (70904504/108,12.03.2018). Çalışma Helsinki Bildirgesi ilkelerine uygun olarak tamamlanmıştır. Akdeniz Üniversitesi Tıp Fakültesi Periton Diyalizi Polikliniği ve Hemodiyaliz Kliniğinde tedavi gören ve takip edilen 18 yaş üzeri, 
hemodiyaliz veya periton diyalizi uygulayan hastalar çalışmaya alınmıştır. Çalışmadan çıkarılma kriteri kronik böbrek hastalığına bağlı olmaksızın herhangi bir kemik mineral bozukluğu hastalığı tanısı bulunmasıdır.

Hastaların hastanemizde aynı yöntem ve cihaz ile yapılan biyokimya parametreleri ve DEXA raporları retrospektif incelenmiştir. Aynı zamanda KBH nedeni, yaşı, cinsiyeti, eşlik eden hastalığı, vücut ağırlığı, renal replasman tedavi süresi, renal replasman tedavinin etkinliği, önceden steroid tedavisi alıp almadığı, kırık öyküsü, sigara tüketimi, menopoz yaşı, fosfat düşürücü ilaç kullanıp kullanmadı̆̆ı dosyalarından bulunarak değerlendirilmiştir

Biyokimyasal olarak kalsiyum (ca), fosfor (p), alkalen fosfataz (ALP), parathormon (PTH), hemoglobin, kreatinin, bikarbonat, 25 hidroksi vitamin $\mathrm{D}$, albümin değeri incelenmiştir.

\section{ISTATİSTIKSEL DEĞERLENDİRME}

Tanımlayıcı istatistikler frekans, yüzde, ortalama, standart sapma, medyan, minimum, maksimum değerleri ile sunulmuştur. Kategorik verilerin analizinde beklenen değerin 5 ’ten küçük olduğu hücre yüzdesi \%20'den büyükse Fisher's Exact Test (Fisher'in Kesin Testi), küçük ise Pearson ChiSquare (Pearson Ki-Kare) Testi kullanılmıştır. Normallik varsayımı Shapiro Wilk Testi ile kontrol edilmiştir. İki grubun sayısal verileri arasındaki farkın analizinde veriler normal dağılıma uyduğu durumda Independent Samples t test (Bağımsız İki Örneklem t Testi), uymadığı durumda Mann-Whitney U Testi kullanılmıştır. Sayısal veriler arasındaki ilişkiler non-parametrik Spearman Korelasyon Testi veya parametrik Pearson Korelasyon Testi ile değerlendirilmiştir. Osteoporoz ile ilişkili bağımsız risk faktörlerinin belirlenmesi için Lojistik Regresyon Analizi yapılmıştır. Analizler SPSS 23.0 programı ile yapılmıştır. $\mathrm{P}<0,05$ istatistiksel olarak anlamlı kabul edilmiştir.

\section{BULGULAR}

Çalışmamıza Akdeniz Üniversitesi Tıp Fakültesi Periton Diyalizi Polikliniğinde ve Hemodiyaliz Kliniğinde takipli olup, DEXA'sı çekilen hastalar alınmıştır. Periton diyalizi grubunda 37 ve hemodiyaliz grubunda 37 hasta çalışmaya alınmıştır. Çalışmamıza katılan 74 hastanın 32 (\%43)'sinde osteoporoz tespit edilmiş olup periton diyaliz uygulayan 13 $(\% 35,1)$ hastada, hemodiyaliz uygulayan $19(\% 51,4)$ hastada osteoporoz saptanmıştır. Osteoporoz sıklı̆̆ı açısından periton ve hemodiyaliz hastalarında fark saptanmamıştır $(\mathrm{p}=0,159)($ Tablo 1.1).

Çalışmamızda osteoporoz gelişmesini etkilediğini düşündüğümüz parametrelerle osteoporoz gelişen ve gelişmeyen hastalar arasındaki ilişkiyi gösteren istatistiksel analiz sonucu Tablo 1.2'de gösterilmiştir.

Çalışmamızda istatistiksel olarak baktığımız zaman incelediğimiz parametrelerde kalsiyum içermeyen fosfat bağlayıcı
Tablo 1.1. Diyaliz tipi - osteoporoz ilişkisi

\begin{tabular}{lccc}
\hline \multirow{2}{*}{ Diyaliz } & \multicolumn{2}{c}{ Osteoporoz } & \multirow{2}{*}{ P } \\
\cline { 2 - 3 } & Var & Yok & \\
\hline Periton diyalizi & $13(\% 35,1)$ & $24(\% 64,9)$ & \multirow{2}{*}{0,159} \\
\hline Hemodiyaliz & $19(\% 51,4)$ & $18(\% 48,6)$ & \\
\hline
\end{tabular}

kullanımı, düşük vücut ağırlı̆gı, düşük kalsiyum ve $25 \mathrm{OH}$ Vitamin D düzeyi osteoporoz ile ilişkili olarak saptanmıştır.

Diyaliz tipi, kalsiyum içermeyen fosfat bağlayıcı kullanımı, vücut ağırlı̆̆ını içeren regresyon analizler yapıldığı zaman osteoporoz gelişimi için en önemli faktör vücut ağırlığı olarak saptanmıştır (Tablo 1.3).

Çalışmamızda periton diyalizi ve hemodiyaliz uygulayan hastaları kıyasladığımız zaman periton diyaliz yapan hastalarda \%35 oranında osteoporoz daha az gözlenmiştir. Fakat istatistiksel olarak anlamlı olarak tespit edilmemiştir.

Osteoporoz gelişimini etkileyen risk faktörlerini diyaliz tipine göre incelediğimiz zaman her iki grupta bazı parametrelerde farklılık saptanmıştır. Periton diyalizi uygulayan hastalarda fosfat bağlayıcı ilaç kullanımı osteoporozdan koruyucu olarak tespit edilmiştir.

Periton diyalizi yapan hastalarda menopoza girme yaşı, hastaların kt/v oranı, $25 \mathrm{OH}$ vitamin $\mathrm{D}$ düzeyi hemodiyaliz yapan hastalardan farklı olarak tespit edilmiş olup, istatistiksel olarak anlamlı saptanmamıştır. Hemodiyaliz yapan hastalarda serum PTH ve kalsiyum konsantrasyonu periton diyalizi yapan hastalardan farklı tespit edilmiş olup, istatistiksel olarak anlamlı bulunmamıştır.

Çalışmaya katılan tüm hastaları incelediğimiz zaman osteoporozu en çok etkileyen durum hastanın vücut ağırlığıdır. Vücut ağırlığındaki azalma osteoporoz siklığında artışla beraberdir.

\section{TARTIŞMA}

KBH'na bağlı kemik mineral bozuklukları önemli bir sağlık sorunudur. KBH-MBD nedenlerinden birisi olan osteoporoz KBH'na sahip hastalarda yaklaşık olarak \%53 oranında tespit edilmiştir (4). Bizim çalışmamızda da literatürdeki oranlara benzer olarak diyaliz hastalarında $\% 43$ oranında osteoporoz tespit edilmiştir. Hemodiyaliz yapan hastalarda $\% 51,4$; periton diyalizi yapan hastalarda $\% 35$, 1 olarak tespit edilmiştir.

Bizim çalışmamızda istatistiksel olarak anlamlı olmasa da periton diyalizi uygulayan hastalarda osteoporoz daha az gözlenmiştir. Bunun nedeni çalışmaya katılan hasta sayısının az olması olabilir. 2014 yılında yayınlanan bir çalışmada hemodiyaliz yapan hastalarda periton diyalizi uygulayan hastalara göre kalça kırığı riski daha yüksek saptanmıştır (7). 


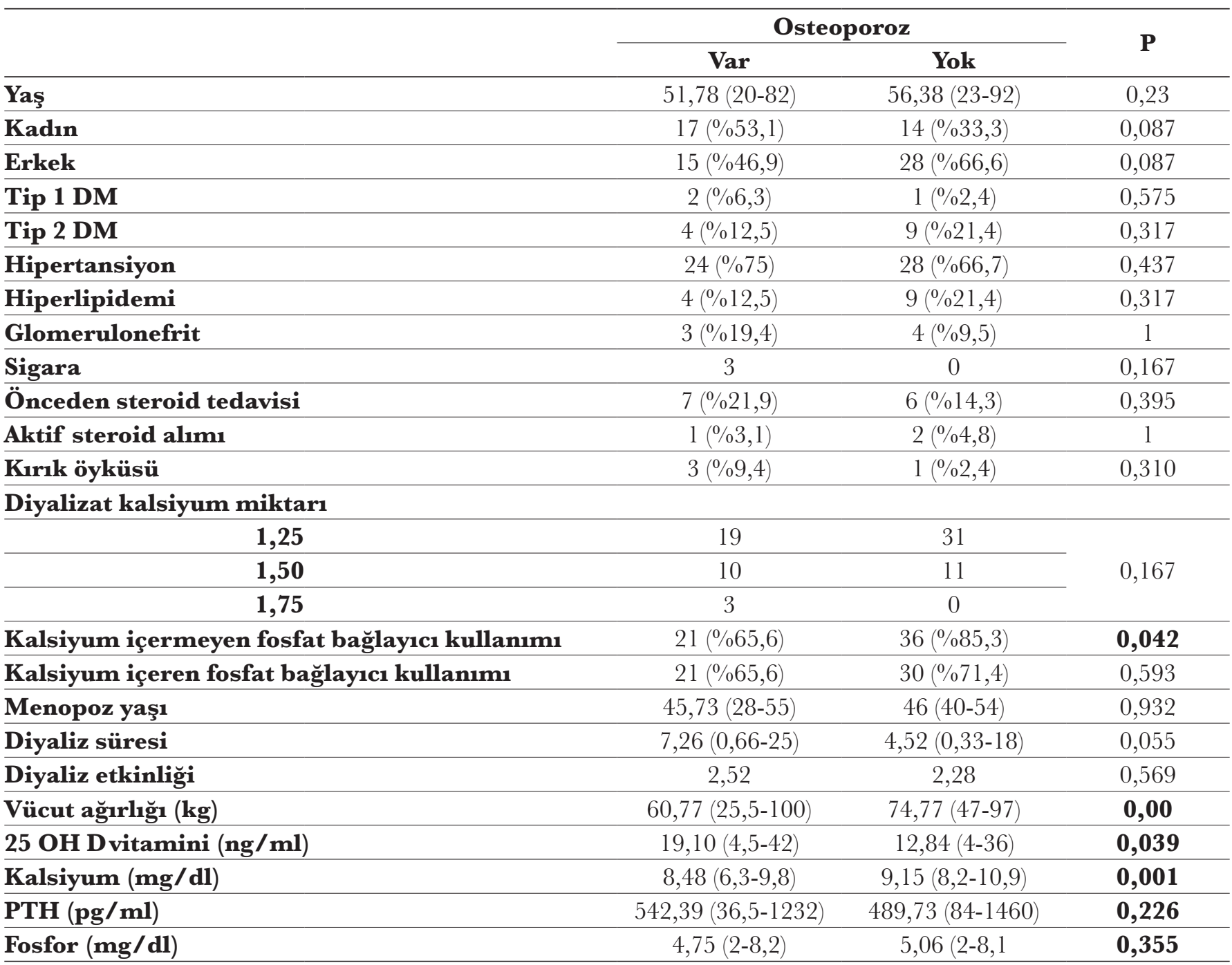

DM: Diyabetes mellitus, PTH: Parathormon.

Tablo 1.3. Regresyon analizi: osteoporoz ile ilişkili faktörlerin regresyon analizi.

\begin{tabular}{lc}
\hline $\mathbf{2 5}$ OH vitamin D3 $(\mathbf{m g} / \mathbf{d l})$ & 0,301 \\
\hline Vücut ağırlığı $(\mathbf{k g})$ & 0.03 \\
\hline Kalsiyum içermeyen fosfat bağlayıcı kullanımı & 0,700 \\
\hline Diyaliz tipi & 0,500 \\
\hline
\end{tabular}

Dusceac ve arkadaşlarının 2018 ylında yayınladığı bir çalışmada hemodiyaliz uygulayan hastaların kemik mineral dansitesinden bağımsız olarak daha düşük trabeküler kemik skoruna sahip olduğunu yayınlamıştır. Trabeküler kemik skoru genel popülasyonda kemik mineral dansitesinden bağımsız olarak kişilerin kemik kırık riskini göstermekte kullanılan bir skorlamadır. Bu çalışmada normal böbrek fonksiyonuna sahip kişilerle hemodiyaliz uygulayan hastalar karşılaştırılmış olup anlamlı olarak lumbal vertebralarda trabeküler kemik skorunun hemodiyaliz uygulayan hastalarda daha düşük olduğunu göstermiştir. Bu skorlamanın amacı hastaların 10 yıllık fraktür riskini göstermektir (8).

Geçmiş yıllarda osteoporoz tanısı için altın standart olarak önerilen kemik biyopsinin kullanım zorluğu, DEXA kullanımı ile ilgili yeterli veri olmaması ve tanı sonrası SDBH olan hastalarda medikal tedavilerin yetersiz oluşu nedeniyle osteoporoz taraması sık yapılmamaktaydı. Ancak 2017 KDIGO kılavuzunda osteoporoz için risk faktörleri 
olan KBH'na sahip hastalarda DEXA ile tarama yapılması önerilmektedir (9).

Altmış beş yaş üstü 94 bin hastanın değerlendirildiği bir çalışmada eşlik eden astım, hipertansiyon, periferik arter hastalığ varlığının ve cinsiyetin, osteoporozla ilişkili olduğu saptanmıştır (10). Cinsiyetin osteoporoz sıklı̆̆ı açısından önemli olma nedeni menopoza girene kadar hormonal faktörlerin kadınları osteoporozdan koruyor olması olabilir. SDBH olan hastalarda kalça kırığı riskinin daha yüksek olduğu gözlenmiştir. Bu çalışmaya göre SDBH'na sahip olmak osteoporoz için riskli saptanmıştır.

2004 yllında yapılan bir çalışmada düşük vücut ağırlığına sahip periton diyaliz yapan hastalarda osteoporozun daha sık gözlendiği saptanmıştır (11). Bizim çalışmamızda da osteoporozu olan hemodiyaliz ve periton diyalizi uygulayan hastaları incelediğimizde en önemli faktörün vücut ağırlığ1 olduğu tespit edilmiştir. Yapılan bu çalışma da böbrek hastalığının etyolojisinde yer alan diyabetes mellitus, hipertansiyonu olanlarda farklı oranlarda tespit edilmiş, fakat istatistiksel olarak anlamlı bulunmamıştır. O dönem yapılan çalışmada periton diyalizi yapan osteoporozu olan hastaların diyalizat kalsiyum oranı 1,25 mmol/l'den daha yüksek saptanmıştır. Düşük diyalizat kalsiyum solüsyonları kullanımının osteoporozdan koruyucu olduğu yapılan bir çalışmada gösterilmiştir (11). Osteoporozdan koruma nedeni hastaların kalsiyum konsantrasyonlarını arttırmaması olabilir. Bu bağlamda bakarsak periton diyalizi yapan hastalarda kalsiyum içermeyen fosfat bağlayıcı kullanımı bu hastaları osteoporozdan koruyor olabilir.

2009 yılında yapılan bir çalışmada hemodiyaliz yapan hastalarda osteoporozu etkileyen faktörler incelenmiştir. Bu çalışmanın sonucuna göre vücut ağırlığı, vücut kitle indeksi, cinsiyet ve post menopozal veya amenoreik olma durumu osteoporoz açısından önemli tespit edilmiştir. Fakat hemoglobin düzeyi ve yaşın pek etkili olmadığı saptanmıştır.

Bizim çalışmamızda en önemli faktör vücut ağırlığı olarak saptanmıştır. Fakat çalışmadaki hasta sayısının az olması nedeni ile diğer faktörler arasında anlamlı farklılık olmamış olabilir. Bu çalışmada serum PTH seviyesi osteoporoz ile negatif korelasyon göstermektedir. Hatta bazı hastalarda paratiroidektomi yapılmıştır. Bu çalışma da hastaları PTH düzeyine göre gruba ayırmıs olup, PTH'ı yüksek olan hastalarla düşük hastalar arasında osteoporoz açısından anlamlı fark gözlenmiştir (12).

SDBH'na sahip hastalarda osteoporozu olan hastalarm koroner arter hastalığı açısından daha risklidir. Yapılan bir çalışma da bu hastaların osteoporozunun olması kardiyovasküler hastalık açısından riskli saptanmış olup, eşlik eden hipertansiyon ve erkek cinsiyet bu riski arttırmaktadır. Bizim çalışmamızda da eşlik eden hipertansiyon varlığı fazla olup, istatistiksel olarak anlamlı olmasa da bu has- talarda osteoporoz da sik gözlenmektedir. Osteoporoz bu hastalarda sadece kırık riski olması ile değil kardiyovasküler mortalite ile ilişkili olması nedeni ile de önemlidir (11).

Bizim çalışmamızda istatistiksel olarak anlamlı olmasa da periton diyalizi yapan hastalarda osteoporoz daha az gözlenmiştir. İstatistiksel olarak anlamlı olmamasının nedeni çalışmaya katılan hasta sayısının az olması olabilir. Fakat 2014 yılında yapılan bir çalışmada 51.000 hasta incelenmiştir. Bu çalışmada hemodiyaliz uygulayan hastalarda periton diyalizi uygulayan hastalara göre kalça kırı̆̆ı daha sık tespit edilmiştir. Bu çalışmada kalça kırığı risk faktörleri arasında yaş, kadın cinsiyet, hemodiyaliz uygulamak kalça kırığı ile ilişkili olarak saptanmıştır (13). Bizim çalışmamızda da osteoporoz üzerine etkili olan faktörler arasında istatistiksel olarak en belirgin faktörün vücut ağırlığı olduğu görülmüştür.

Osteoporoz tedavisi için kullanılan tedaviler arasında selektif östrojen reseptör modulatörü, bifosfanat, PTH analogları, denosumab yer almaktadır. Bu tedavilerin birçoğu son dönem böbrek hastalığı olan kişilerde kullanılamamaktadır ya da kullanılması ile ilgili yeterli çalışma bulunmamaktadır. Aynı zamanda bu hastalarda osteoporoza yol açan mekanizmalar sadece osteoporoz ile ilişkili olmayıp kardiyovasküler hastalık riskini de arttırmaktadır. Yakın zamanlarda yapılan çalışmalarda osteoporoz oluşumuna yol açan mekanizmalardan sorumlu olan hormonlardan fosfatürik etkisi olan fibroblast büyüme faktörü (FGF-23) molekülünün kardiyovasküler komplikasyonlar ile de ilişkili olduğu gözlenmiştir. FGF-23 adlı hormon kemik üzerindeki etkilerini klotho adlı protein üzerinden sağlamaktadır. Fakat klothodan proteininden bağımsız olarak kardiyovasküler mortaliteyi arttırıcı etkisi bulunmaktadır (10).

Osteoporoz gelişmesi önemli risk faktörlerden biri beslenmedir. Sadece vitamin D eksikliği osteoporoz gelişmesinde sorumlu tek vitamin eksikliği olmayıp son zamanlarda yapılan çalışmalarda K vitamin eksikliği de suçlanmaktadır. SDBH olan hastalarda düşük K vitamin düzeyi bu hastalarda hem kemik mineral dansitesinde düşüklük hem de inflamasyonla ilişkili saptanmıştır. Aynı zamanda bu hastalarda artmış kemik fraktür riski ile ilişkili gözlenmiştir (14).

KBH sonucu oluşan üremik toksinler hastalığın birçok morbiditesi ve mortalitesinden sorumludur. Dolayısıyla kemik mineral hastalığına gelişmesinde katkı bulunmaktadır. Patogenez gelişmesinde etkili olmasından dolayı bu toksinleri inhibe eden tedavi modaliteleri üzerinde ileri araştırmalar yapılması gerekmektedir (15).

\section{SONUÇ}

Sonuç olarak araştırmamızda hemodiyaliz ve periton diyalizi uygulayan hastalarda osteoporoz ile ilişkili en önemli risk faktörü vücut ağırlığı olarak saptanmıştır. Araştırmaya 
katılan hasta sayısının az olması nedeni ile osteoporoz ile ilişkili olması muhtemel olan birçok faktör anlamlı saptanmamıștır. SDBH olanlarda osteoporozun önemli bir mortalite ve morbidite nedeni olması nedeni ile risk faktörlerini belirlemek önemlidir. Bu açıdan riskli olan hastalarda uygun renal replasman tedavi yöntemi belirlenmeli ve osteoporozdan kaçınmalıdır. Bu hastalar osteoporoz açısından da gerektiği şekilde incelenmeli ve tedavi edilmelidir.

Bizim çalışmamızın en önemli limitasyonu hasta sayısının az olmasıdır. Yeni değişen kılavuzlarla beraber KBH'na bağlı osteoporoz için risk faktörlerini belirlemek amacı ile prospektif hasta sayısının daha fazla olduğu çalışmalara ihtiyaç vardır.

\section{KAYNAKLAR}

1. Levey AS, Eckardt KU, Tsukamato Y, Levin A, Coresh J,Rossert J, Zeeuw D, Hostetter T, Lameire N, Eknoyan G. Definition and classification of chronic kidney disease: a position statement from Kidney Disease: Improving Global Outcomes (KDIGO). Kidney Int 2005; 67: 2089100 .

2. Levey AS, de Jong PE, Coresh J, Nahas ME, Astor BC, Matsushita K, Gansevoort RT, Kasiske BL, Eckardt KU. The definition classification and prognosis of chronic kidney disease: a KDIGO Controversies Conference report. Kidney Int 201 1; 80(1): 17-28.

3. Covic A, Voroneanu L, Apetrii M. PTH and/or Bone Histology: Are We Still Waiting for a Verdict From the CKD-MBD Grand Jury? Am J Kidney Dis 2016; 67(4): 535-8.

4. Festuccia F, Jafari MT, Moioli A, Fofi C, Barberi S, Amendola S, Sciacchitano S, Punzo G, Mene P. Safety and efficacy of denosumab in osteoporotic hemodialysed patients, J Nephrol 2017; 30(2): 271-9.

5. Bianchi ML, Leonard MB, Bechtold S, Högler W, Mughal ZM, Schönau E, Sylvester FA, Vogiatzi M, Heuvel-Eibrink MMV, Ward L. Bone health in children and adolescents with chronic diseases that may affect the skeleton: the 2013 ISCD Pediatric Official Positions. J Clin Densitom 2014; 17(2): 281-94.

6. Bishop N, Arundel P, Clark E, Dimitri P, Farr J, Jones G, Makitie O, Munns CF, Shaw N. Fracture prediction and the definition of osteoporosis in children and adolescents: the ISCD 2013 Pediatric Official Positions. J Clin Densitom 2014; 17(2): 275-80

7. Mathew AT, Hazan A, Jhaveri KD, Block GA, Chidella S, Rosen L, Wagner J, Fishbane S. Increasing hip Fractures in patients receiving hemodialysis and peritoneal dialysis. Am J Nephrol 2014; 40(5): 451-7.
Etik Komite Onayı: Akdeniz Üniversitesi Tip Fakültesi Klinik Araştırmalar Etik Kurulu Başkanlığı tarafından değerlendirmeye alınarak yazılı olarak onaylanmıștır (70904504/108,12.03.2018). Çalışma Helsinki Bildirgesi ilkelerine uygun olarak tamamlanmıştır.

Çıkar Çatışması: Yazarların beyan edecek çıkar çatışması yoktur.

Finansal Destek: Yazarlar bu çalışma için finansal destek almadıklarını beyan etmişlerdir.

8. Dusceac R, Niculescu DA, Dobre R, Dragne MC, Tacu C, Peride I, David C, Checherita I, Poiana C. Chronic hemodialysis is associated with lower trabecular bone score, independent of bone mineral density: a case control study Arch Osteoporos 2018; 13;13(1): 125.

9. KDIGO 2017, Chapter 3.2 Diagnosis of CKD-MBD bone.

10. Yu TM, Lin LC, Shu KH, Liu YL, Chen CH, Huang ST, Kao CH. Increased risk of cardiovascular events in end stage renal disease patients with osteoporosis: a nation wide population- based cohort study. Osteoporos Int 2015; 26(2): 785-93.

11. Ersoy FF, Gültekin M, Karayalçın B, Passadakis SP, Tam P, Evaggelos DM, Katopodis PK, Ozener, Akçiçek F, Camsari T, Ateş K, Ataman R, Vlachojannis JG, Dombros AN, Utas C, Akpolat, Bozfakioğlu S, Wu G, Karayaylali I, Arinsoy T, Stathakis PC, Yavuz M, Tsakiris JD, Dimitriades CA, Yilmaz ME, Yardimsever M, Oreopoulos DC. Bone Mineral Density and its correlation with clinical and laboratory factors in chronic peritoneal dialysis patients, J Bone Miner Metab 2006; 24: 79-86.

12. Huang GS, Chu TS, Lou MF, Hwang SL, Yang RS. Factors associated with low bone mass in the hemodialysis patients- a cross sectional correlation study BMC Musculoskelet Disord 2009; 10: 60.

13. Lin ZZ, Wang IJ, Chung CR, Huang PC, Su BA, Cheng KC, Chio CG, Chien CG. Epidemiology and mortality of hip fracture among patients on dialysis: Taiwan National Cohort Study. Bone 2014; 64: 235-9.

14. Evenepoel P, Claes K, Meijers B, Laurent M, Bammens B, Naesens M, Sprangers B, Pottel H, Cavalier E, Kuypers D. Poor Vitamin K Status Is Associated With Low Bone Mineral Density and Increased Fracture Risk in EndStage Renal Disease. J Bone Miner Res 2019; 34(2): 26269.

15. Yamamoto S. Fragility Fractures in Hemodialysis Patients. Uremic toxins-related abnormal bone metabolism, Clin Calcium 2018; 28(8): 1093-100. 